\title{
The role of post-mortem computed tomography in assault victims with head trauma in central South Africa
}

\author{
Authors: \\ Nantes Combrinck ${ }^{1}$ \\ Stefan Jansen van Vuuren ${ }^{2}$ \\ Affiliations: \\ ${ }^{1}$ Department of Clinical \\ Imaging Sciences, \\ University of the Free State, \\ South Africa \\ ${ }^{2}$ Department of Forensic \\ Pathology, University of the \\ Free State, South Africa \\ Corresponding author: \\ Nantes Combrinck, \\ doc.nantes@gmail.com \\ How to cite this article: \\ Combrinck $\mathrm{N}$. The role of \\ post-mortem computed \\ tomography in assault victims \\ with head trauma in central \\ South Africa. S Afr J Rad. \\ 2017;21(1), a1164. https:// \\ doi.org/10.4102/sajr. \\ v21i1.1164

\section{Copyright:} \\ (c) 2017. The Authors. \\ Licensee: AOSIS. This work \\ is licensed under the \\ Creative Commons \\ Attribution License.
}

Background: The role of post-mortem computed tomography (PMCT) has been studied extensively, though not in South Africa. In many countries, it has become an important adjunct to the routine forensic examination.

Objectives: The study compared the findings of PMCT and conventional autopsy in victims of assault who presented with head injuries. The outcomes were compared to similar studies published internationally.

Method: A non-randomised prospective analytical study method was utilised. Victims of assault who presented with head injuries underwent PMCT, followed by a conventional autopsy. The findings were compared.

Results: PMCT proved superior for detecting bony injuries. Autopsy was more effective in detecting subdural haemorrhages. No major statistical difference was found in detecting intraaxial injuries. More injuries were detected in total by combining the findings of PMCT and autopsy. Several ethical and logistical problems were identified, mainly resulting from the computed tomography (CT) scanner not being in the same facility as the forensic laboratory. Our findings were similar to those of other published studies.

Conclusion: PMCT is an important augmentation to conventional autopsy of trauma victims and could add valuable diagnostic information to the forensic examination. A CT scanner on site would eliminate the logistical and ethical problems identified during the study.

Note: A selection of conference abstracts: RSSA/SASPI Paediatric Imaging Congress, 03-06 November 2016, Spier Estate, Stellenbosch South Africa. Faculty collaborators: Professor Kassa Darge (Body Imaging, University of Pennsylvania, Philadelphia, USA), Professor Edward Lee (Thoracic Imaging, Harvard University, USA), Professor Beverley Newman (Cardiac Imaging, Stanford University, California, USA), Professor Kimberly Applegate (Image Gently and Body Imaging, Emory University, Atlanta, USA) and Professor Savvas Andronikou (Thoracic Imaging, University of Bristol, UK) supported by South African Paediatric Radiologists, co-ordinated by Dr Jaishree Naidoo, President of the African Society of Paediatric Imaging and Head of Division of Paediatric Radiology, Charlotte Maxeke Johannesburg Academic Hospital. 